\title{
CONTAGEM DE CÉLULAS SOMÁTICAS, COMPOSIÇÃO E CONTAGEM \\ BACTERIANA TOTAL DO LEITE DE PROPRIEDADES LEITEIRAS NOS MUNICÍPIOS DE MIRANDA DO NORTE, ITAPECURÚ- MIRIM E SANTA RITA, MARANHÃO
}

\section{L.M. Lacerda1, R.A. Mota ${ }^{2}$, M.J. de Sena ${ }^{2}$}

1Universidade Estadual do Maranhão, Centro de Ciências Agrárias, Departamento de Patologia, CP 9, CEP 65062-708, São Luís, MA. Brasil. E-mail: lenkalacerda@yahoo.com.br

\section{RESUMO}

\begin{abstract}
Objetivou-se com este estudo avaliar a contagem de células somáticas (CCS), composição e contagem bacteriana total (CBT) sobre a qualidade do leite produzido em propriedades leiteiras de Miranda do Norte, Itapecurú-Mirim e Santa Rita, Estado do Maranhão. Verificou-se no período A que a média de CCS foi de 2.236 .700 células $/ \mathrm{mL}, 3,87 \%$ de gordura, 3,19\% de proteína, 4,36\% de lactose, $12,25 \%$ de EST, 8,55\% de ESD (\%) e CBT de 677,90 UFC/ $\mathrm{mL}$, e no período B a média de CCS foi de 2.629 .950 células / $\mathrm{mL}, 3,87 \%$ de gordura, 3,27\% de proteína, 4,45\% de lactose, 13,19\% de EST, 8,74\% de ESD e CBT de 8421,35 UFC/mL. Quanto à sazonalidade, as médias de CCS e CBT foram mais elevadas no período B do que no período A.
\end{abstract}

PALAVRAS-CHAVE: Qualidade do leite, IN N 51, higiene.

\section{ABSTRACT}

SOMATIC CELL COUNTS, COMPOSITION AND TOTAL BACTERIAL COUNTS OF MILK FROM DAIRY FARMS IN THE CITIES OF MIRANDA DO NORTE, ITAPECURÚ-MIRIM AND SANTA RITA, MARANHÃO STATE, BRAZIL. The aim of this study was to evaluate somatic cell counts (SCC), composition and total bacterial counts (TBC) of milk from dairy farms in Miranda do Norte, Itapecurú-Mirim and Santa Rita, all located in Brazilian Maranhão state. In the A period, it were verified means of 2,236,700 somatic cells $/ \mathrm{mL} ; 3.87 \%$ fat; $3.19 \%$ protein; $4.36 \%$ lactose; $12.25 \%$ (TS); $8.55 \%$ non-fat solids (NFS) and 677.90 clonies forming unit (CFU)/mL. In the winter period means were $2,629,950$ cells $/ \mathrm{mL} ; 3.87 \%$ fat; $3.27 \%$ protein; $4.45 \%$ lactose; $13.19 \%$ TS; $8.74 \%$ NFS and $8,421,35 \mathrm{CFU} / \mathrm{mL}$. Regarding sazonality, both SCC and TBC means were higher during the period $\mathrm{B}$ than during the period A.

KEY WORD: Milk quality, IN No 51 , higyenic.

\section{INTRODUÇÃO}

As células somáticas do leite originam-se do sangue (linfócitos, macrófagos e neutrófilos) e células epiteliais de descamação da própria glândula mamária presentes no leite. Essas células são um indicativo da ocorrência de inflamação intramamária e podem ser usadas para distinguir uma glândula mamária infectada de uma não-infectada (SANTOS; FonSECA 2007).

A contagem de células somáticas do rebanho e do tanque de expansão deve ser vista como ferramenta extremamente valiosa eque, entre outras finalidades, pode-se citar: o monitoramento da prevalência de mastite subclínica no rebanho, especialmente aquelas causadas por micro-organismos contagiosos, denotativo da qualidade do leite cru para a indústria; indicação das condições higiênicas sob as quais o leite foi produzido nas propriedades; possibilidade de estimativas das perdas da produção deleite; orientação do produtor para tomada de decisões a fim de prevenir a transmissão da doença durante a lactação e a identificação de vacas para tratamento, secagem e descarte (LANGONI, 2000).

O Ministério da Agricultura, Pecuária e Abastecimento (MAPA), por intermédio do Departamento de Inspeção de Produtos de Origem Animal (DIPOA), publicou a Instrução Normativa Nº51 - IN N51 no

$\overline{{ }^{2} \text { Universidade Federal Rural de Pernambuco, Departamento }}$ de Medicina Veterinária, Recife, PE, Brasil. 
Diário Oficial da União, em 18 de setembro de 2002. Esse regulamento normatiza a produção, estabelecendo os critérios e parâmetros de identidade e qualidade do leite, desde a ordenha, o resfriamento na propriedaderural e seu transporte granel, incluindo requisitos físico-químicos e microbiológicos, contagem de células somáticas (CCS) e composição. Com isto acredita-se em uma melhor remuneração do produtor e melhoria da qualidade do leite consumido no Brasil, além da adequação do produto aos padrões internacionais visando ampliar as exportações (LiMA et al., 2006).

Portanto, o objetivo deste estudo foi avaliar a contagem de células somáticas, composição e contagem bacteriana total do leite de propriedades leiteiras de Miranda do Norte, Itapecurú-Mirim e Santa Rita, Estado do Maranhão, em diferentes períodos do ano.

\section{MATERIAL E MÉTODOS}

Para determinação da qualidade do leite foram selecionadas, aleatoriamente, 20 propriedades produtoras de leite, localizadas nos municípios de Miranda do Norte, Itapecurú-Mirim e Santa Rita, Estado do Maranhão, representando pequenos, médios e grandes produtores, com ordenha manual e mecânica, durante os períodos de agosto a dezembro de 2006 (período A) e de janeiro a julho de 2007 (período B).

As amostras eram representadas por um "pool" de cada propriedade, sendo colhidos aproximadamente $40 \mathrm{~mL}$ em frascos estéreis de $50 \mathrm{~mL}$ com pastilha Bronopol (2-bromo-2-nitropropano-1,3-diol e natamicina). Estas foram colocadas em caixas isotérmicas contendo gelo reciclável, mantidas na temperatura de $7^{\circ} \mathrm{C}$ e enviadas ao Laboratório de Qualidade do Leite do Centro dePesquisa em Alimentos da Escola de Medicina Veterinária da Universidade Federal do Goiás - UFG, para serem submetidos às análises de teor de gordura, proteína, lactose, EST, ESD e contagem de células somáticas (CCS).

Para CBT foram colhidos aproximadamente 40 $\mathrm{mL}$ de leite, em frascos estéreis contendo quatro gotas do conservante azidiol (cloranfenicol, azida sódica, citrato de sódio e álcool etílico), em seguida os frascos foram tombados por 6 vezes, depois foram colocados em caixas isotérmicas contendo gelo reciclável, mantidas a $7^{\circ} \mathrm{C}$ e enviados ao Laboratório de Qualidade do Leite do Centro de Pesquisa em Alimentos da Escola de Medicina Veterinária da Universidade Federal do Goiás - UFG, onde foram submetidas à análise de Contagem Bacteriana Total, por meio equipamento Bactoscan FC (Foss bEletric A/S. Hillerod, Denmark) com capacidade de análise de 50 amos- tras/hora e cujo princípio analítico baseia-se na citometria de fluxo (BROUNTIN, 2004).

Para a análise dos dados foram obtidas distribuições absolutas, percentuais e as medidas estatísticas: média, mediana, desvio padrão, coeficiente de variação, valor mínimo e valor máximo e utilizados os teste: Wilcoxon de Postos Sinalizados, teste t-Student pareado e o teste $\mathrm{t}$-Student para amostras independentes com variâncias iguais ou desiguais (Técnicas de estatística indiferencial) (AltMAN; HALL 1991, Z AR, 1999).

\section{RESULTADOS E DISCUSSÃO}

ACCS no período A variou de 168.000 células $/ \mathrm{mL}$ a 6.211.000 células/ $\mathrm{mL}$, com média de 2.236 .700 células/mL e no período B variou de 767.000 células/ $\mathrm{mL}$ a 10.198.000 células/ $\mathrm{mL}$ com média de 2.629.950 células $/ \mathrm{mL}$, sendo que $65 \%$ das amostras no período Ae $85 \%$ das amostras no período Bestavamacima dos padrões preconizados pela Instrução Normativa n'51/ MAPA (BRASIL, 2002) para a região Nordeste, que estabelece um limite máximo de 1.000 .000 células/mL a partir de junho de 2007.

Com relação à sazonalidade, as médias e as medianas de CCS foram correspondentes mais elevadas no período $\mathrm{B}$ do que no período $\mathrm{A}$ e a variabilidade expressa através do coeficiente de variação se mostrou bastante elevada desde que a referida medida foi no mínimo $78,01 \%$. O aumento da CCS período B, observado nos municípios estudados pode ser justificado por ser um período que apresenta temperaturas elevadas, alta umidade do ar e chuvas periódicas, resultando em maior exposição das extremidades dos tetos aos micro-organismos, favorecendo o aparecimento de novas infecções (Tabela 2).

Pode-se observar que a CCS na estação verão apresentou até 1.000 .000 células / $\mathrm{mL}$ em sete $(35,0 \%)$ propriedades e acima de 1.000 .000 células $/ \mathrm{mL}$ em 13 $(65,0 \%)$ propriedades, enquanto que na estação inverno apenas três $(15,0 \%)$ propriedades apresentaram CCS até 1.000 .000 células/mL e 17 (85\%) propriedades tinham valores acima de 1.000 .000 células $/ \mathrm{mL}$.

Resultados semelhantes foram observados por Araújo et al. (2006) que citaram que a média da CCSno período B foi estatisticamente superior $(p<0,05)$ àquela observada no período $\mathrm{A}$ e enfatizam que no período chuvoso há formação de áreas alagadas e presença de lamas no habitat das vacas, favorecendo as infecções por micro-organismos ambientais. Segundo Viana (2000), BARBOSA et al. (2007), além da presença de infecções intramamárias e fatores intrínsecos como raça, idade da vaca e estágio de lactação, outros fatores extrínsecos podem interferir na CCS, como época do ano e estresse climático. 
Tabela 1 - Distribuição das propriedades leiteiras nos municípios de Miranda do Norte, Itapecurú-Mirim e Santa Rita, MA, analisadas segundo as variáveis relacionadas ao manejo da ordenha.

\begin{tabular}{|c|c|c|}
\hline Variável & $\mathrm{N}$ & $\%$ \\
\hline \multicolumn{3}{|c|}{ - Realização pré e/ou pós - dipping } \\
\hline Sim & 12 & 60,0 \\
\hline Não & 8 & 40,0 \\
\hline Total & 20 & 100,0 \\
\hline \multicolumn{3}{|c|}{ - Utilização de pano para secagem dos tetos } \\
\hline Sim & 12 & 60,0 \\
\hline Não & 8 & 40,0 \\
\hline Total & 20 & 100,0 \\
\hline \multicolumn{3}{|c|}{ - Limpeza e desinfecção das instalações } \\
\hline Sim & 12 & 60,0 \\
\hline Não & 8 & 40,0 \\
\hline Total & 20 & 100,0 \\
\hline \multicolumn{3}{|c|}{ - Utilização de caneca telada e CMT para diagnóstico de mastite antes da ordenha } \\
\hline Sim & 5 & 25,0 \\
\hline Não & 15 & 75,0 \\
\hline Total & 20 & 100,0 \\
\hline \multicolumn{3}{|c|}{ - Sabe o significado de CCS? } \\
\hline Sim & 2 & 10,0 \\
\hline Não & 18 & 90,0 \\
\hline Total & 20 & 100,0 \\
\hline
\end{tabular}

As altas CCSe CBT observadas no presente estudo podem ser explicadas por falhas no manejo, principalmente no que se refere aos cuidados higiênicosanitários na ordenha, pois, das 20 propriedades estudadas, apenas $12(60 \%)$ tinham como rotina a prática de realizar o pré e/ou pós-dipping, mas a maioria não utilizava desinfetantes adequados; algumas usavam na concentração errada e outras utilizavam somente a água para limpeza do úbere edos tetos. Dessas 12 propriedades, somente $3(15 \%)$ realizavam o pós-dipping pelo fato de ter bezerros ao pée acharem que eles podem ingerir o produto. Com relação à utilização de pano para secagem dos tetos das vacas, $12(60 \%)$ propriedades fazem uso na rotina de ordenha, sendo um risco em potencial por poder veicular micro-organismos patogênicoscausadores demastite e, consequentemente, o aumento da CCS. Somente 12 (60\%) propriedades realizavam limpeza e desinfecção das instalações e o restante das propriedades fazia apenas a retirada dos dejetos nas instalações. Constatou-se, no presente trabalho, que somente 5 (25\%) propriedades utilizavam caneca telada e CMT para diagnóstico de mastite antes da ordenha e apenas dois $(10 \%)$ proprietários afirmaram conhecer o significado de CCS, mas não souberam responder corretamente (Tabela 1).

$\mathrm{Na}$ Tabela 2, verifica-se que, com exceção do percentual de gordura que apresentou médias iguais entre os dois períodos, as demais médias foram correspondentemente mais elevadas período $\mathrm{B}$ do que período A, entretanto diferença significativa ao nível de 5,0\% entre os dois períodos só foi verificada para EST $(\mathrm{p}<0,05)$.

Observou-se que as médias de gordura, proteína, lactose, EST e ESD, tanto no período A quanto no período B, estavam de acordo com os valores preconizados pela IN N51/MAPA. Resultados semelhantes foram observados por BARCELOs et al. (2006) em amostras de leite cru clandestino em Paruapebas, PA; SILVA etal.(2007) em propriedades leiteiras deCatalão, GO eFERreira etal. (2006) em amostras de leite pasteurizado em Jaboticabal,SP. Contudo, diferem deVIDALMARTINS et al. (2005), os quais observaram valores de EST e ESD fora dos padrões exigidos pela IN N ${ }^{\circ}$ 51/ MAPA em amostras de leite UAT de São Paulo.

Na Tabela 3, observa-se que no verão as médias foram mais elevadas entre as propriedades que produziam até 250 L de leite para as variáveis: gordura, CCS e CBT e o contrário ocorreu com as outras variáveis (proteína, lactose, EST e ESD) que apresentaram as médias mais elevadas entre as propriedades que produziam mais de $250 \mathrm{~L}$ de leite, entretanto, a única diferença significativa para esses grupos ocorreu para a CCS $(\mathrm{p}<0,05)$.

Na Tabela 4, observa-se que no período B as médias de gordura, lactose, EST, ESD e CCS foram mais elevadas entre as fazendas que produziam até $250 \mathrm{~L}$ de leite, entretanto, a única diferença significativa entre os dois subgrupos do volume de leite ocorreu para CCS $(\mathrm{p}<0,05)$. 
Tabela 2 - Percentual de gordura, proteína, lactose, EST e ESD segundo a estação do ano (verão e inverno), nas propriedades leiteiras de Miranda do Norte, Itapecurú-Mirim e Santa Rita, MA.

\begin{tabular}{|c|c|c|c|c|}
\hline Variável & Estatísticas & Verão & Inverno & Valor de $\mathrm{p}$ \\
\hline - Gordura (\%) & $\begin{array}{l}\text { Média } \\
\text { Mediana } \\
\text { Desvio padrão } \\
\text { Coeficiente de variação } \\
\text { Mínimo } \\
\text { Máximo }\end{array}$ & $\begin{array}{r}3,87 \\
3,82 \\
0,63 \\
16,28 \\
2,96 \\
5,41\end{array}$ & $\begin{array}{r}3,87 \\
3,83 \\
0,63 \\
16,28 \\
2,96 \\
5,41\end{array}$ & $\mathrm{p}(1)=1,000$ \\
\hline - Proteína (\%) & $\begin{array}{l}\text { Média } \\
\text { Mediana } \\
\text { Desvio padrão } \\
\text { Coeficiente de variação } \\
\text { Mínimo } \\
\text { Máximo }\end{array}$ & $\begin{array}{l}3,19 \\
3,23 \\
0,20 \\
6,27 \\
2,67 \\
3,42\end{array}$ & $\begin{array}{l}3,27 \\
3,23 \\
0,22 \\
6,73 \\
2,90 \\
3,76\end{array}$ & $p(1)=0,239$ \\
\hline - Lactose (\%) & $\begin{array}{l}\text { Média } \\
\text { Mediana } \\
\text { Desvio padrão } \\
\text { Coeficiente de variação } \\
\text { Mínimo } \\
\text { Máximo }\end{array}$ & $\begin{array}{l}4,36 \\
4,39 \\
0,27 \\
6,19 \\
3,42 \\
4,74\end{array}$ & $\begin{array}{l}4,45 \\
4,47 \\
0,24 \\
5,39 \\
4,06 \\
5,11\end{array}$ & $p(1)=0,614$ \\
\hline • EST (\%) & $\begin{array}{l}\text { Média } \\
\text { Mediana } \\
\text { Desvio padrão } \\
\text { Coeficiente de variação } \\
\text { Mínimo } \\
\text { Máximo }\end{array}$ & $\begin{array}{r}12,25 \\
12,36 \\
0,76 \\
6,20 \\
10,61 \\
13,75\end{array}$ & $\begin{array}{r}13,19 \\
13,26 \\
1,06 \\
8,04 \\
11,07 \\
14,57\end{array}$ & $\mathrm{p}(2)=0,009^{*}$ \\
\hline - ESD (\%) & $\begin{array}{l}\text { Média } \\
\text { Mediana } \\
\text { Desvio padrão } \\
\text { Coeficiente de variação } \\
\text { Mínimo } \\
\text { Máximo }\end{array}$ & $\begin{array}{l}8,55 \\
8,77 \\
0,48 \\
5,61 \\
6,97 \\
9,17\end{array}$ & $\begin{array}{l}8,74 \\
8,73 \\
0,41 \\
4,69 \\
7,99 \\
9,93\end{array}$ & $p(1)=0,467$ \\
\hline
\end{tabular}

EST - Extrato Seco Total.

ESD - Extrato Seco Desengordurado.

Na Tabela 5, destaca-se que as médias para gordura foram mais elevadas entre as amostras que tinham mais de 1.000 .000 células $/ \mathrm{mL}$, tanto no período B quanto no período A; a média para lactose foi mais elevada entreas propriedades que tinham até 1.000 .000 células/mL no período $\mathrm{A}$, enquanto que no período $\mathrm{B}$ a média foi mais elevada entre as propriedades que tinham mais de 1.000 .000 células / mL; as médias das variáveis: proteína, EST e ESD foram correspondentemente mais elevados entreas propriedades comaté 1.000 .000 células $/ \mathrm{mL}$ noperíodo AeB, entretanto,nãosecomprovoudiferença significativa entre as propriedades com até 1.000.000 células/mL do que entre as propriedades que tinham mais de 1.000.000/ mL células para nenhuma das variáveis analisadas no período A e B.
Com relação à gordura, resultados semelhantes foram observados por LimA et al. (2006) que verificaram aumento do teor de gordura à medida que a CCS aumentava. Os mesmos autores observaram um aumento deEST, ESD e proteína, com o aumento deCCS, mas uma diminuição quando a CCS estava acima de 1.000 .000 células/mL e aumento da lactose com o aumento da CCS. Ao contrário de BuENo et al.(2005), que verificaram uma redução significativa nos teores de proteína, lactose e EST com o aumento da CCS ecom relação à gordura, constatou-se que praticamente não houve variação entre os intervalos, com diferença significativa apenas entre os intervalos (CCS menor ou igual a 200.000 células/mL e entre 201.000 e 400.000 células $/ \mathrm{mL}$ ). 
Tabela 3 - Percentual de gordura, proteína, lactose, EST e ESD, CCS e CBT, segundo o volume de leite na estação do verão nas propriedades leiteiras de Miranda do Norte, Itapecurú-Mirim e Santa Rita, MA.

\begin{tabular}{|c|c|c|c|c|}
\hline \multirow[t]{2}{*}{ Variável } & \multirow[t]{2}{*}{ Estatísticas } & \multicolumn{2}{|c|}{ Volume do leite (L) } & \multirow[t]{2}{*}{ Valor de $\mathrm{p}$} \\
\hline & & Até 250 & $>250$ & \\
\hline \multirow[t]{3}{*}{ - Gordura (\%) } & Média & 3,94 & 3,66 & $\mathrm{P}^{(1)}=0,413$ \\
\hline & Mediana & 3,89 & 3,60 & \\
\hline & Desvio padrão & 0,69 & 0,37 & \\
\hline \multirow[t]{3}{*}{ • Proteína (\%) } & Média & 3,15 & 3,31 & $\mathrm{P}^{(1)}=0,124$ \\
\hline & Mediana & 3,15 & 3,36 & \\
\hline & Desvio padrão & 0,21 & 0,10 & \\
\hline \multirow[t]{3}{*}{ - Lactose (\%) } & Média & 4,30 & 4,53 & $\mathrm{P}^{(1)}=0,111$ \\
\hline & Mediana & 4,34 & 4,50 & \\
\hline & Desvio padrão & 0,29 & 0,16 & \\
\hline \multirow[t]{3}{*}{ • EST (\%) } & Média & 12,17 & 12,51 & $\mathrm{P}^{(1)}=0,394$ \\
\hline & Mediana & 12,16 & 12,77 & \\
\hline & Desvio padrão & 0,84 & 0,40 & \\
\hline \multirow[t]{3}{*}{ • ESD (\%) } & Média & 8,45 & 8,85 & $\mathrm{P}^{(1)}=0,114$ \\
\hline & Mediana & 8,71 & 8,78 & \\
\hline & Desvio padrão & 0,51 & 0,18 & \\
\hline \multirow[t]{3}{*}{ • CCS X (1000céls./mL) } & Média & $2.644,47$ & $1.013,40$ & $\mathrm{P}^{(2)}=0,012^{*}$ \\
\hline & Mediana & $2.238,00$ & 701,00 & \\
\hline & Desvio padrão & $1.803,48$ & 763,06 & \\
\hline \multirow[t]{3}{*}{ - CBT x (1000 UFC/mL) } & Média & 837,80 & 198,20 & $\mathrm{P}^{(2)}=0,062$ \\
\hline & Mediana & 343,00 & 112,00 & \\
\hline & Desvio padrão & $1.188,56$ & 194,67 & \\
\hline
\end{tabular}

EST - Extrato Seco Total; ESD - Extrato Seco Desengordurado; CCS - Contagem de Células Somáticas; CBT - Contagem Bacteriana Total

Tabela 4 - Percentual de gordura, proteína, lactose, EST, ESD, CCSe CBT, segundo o volume de leite na estação do inverno nas propriedades leiteiras de Miranda do Norte, Itapecurú-Mirim e Santa Rita, MA.

\begin{tabular}{|c|c|c|c|c|}
\hline \multirow[t]{2}{*}{ Variável } & \multirow[t]{2}{*}{ Estatísticas } & \multicolumn{2}{|c|}{ Volume do leite (L) } & \multirow[t]{2}{*}{ Valor de $p$} \\
\hline & & Até 250 & $>250$ & \\
\hline \multirow[t]{3}{*}{ - Gordura (\%) } & Média & 3,94 & 3,65 & \multirow[t]{3}{*}{$\mathrm{p}^{(1)}=0,381$} \\
\hline & Mediana & 3,88 & 3,58 & \\
\hline & Desvio padrão & 0,69 & 0,38 & \\
\hline \multirow[t]{3}{*}{ - Proteína (\%) } & Média & 3,31 & 3,14 & \multirow[t]{3}{*}{$\mathrm{p}^{(1)}=0,123$} \\
\hline & Mediana & 3,35 & 3,17 & \\
\hline & Desvio padrão & 0,21 & 0,18 & \\
\hline \multirow[t]{3}{*}{ - Lactose (\%) } & Média & 4,46 & 4,42 & \multirow[t]{3}{*}{$\mathrm{p}^{(1)}=0,752$} \\
\hline & Mediana & 4,47 & 4,46 & \\
\hline & Desvio padrão & 0,26 & 0,20 & \\
\hline \multirow[t]{3}{*}{ • EST (\%) } & Média & 13,26 & 12,98 & \multirow[t]{3}{*}{$\mathrm{p}^{(1)}=0,622$} \\
\hline & Mediana & 13,38 & 12,49 & \\
\hline & Desvio padrão & 0,99 & 1,35 & \\
\hline \multirow[t]{3}{*}{ • ESD (\%) } & Média & 8,79 & 8,60 & \multirow[t]{3}{*}{$\mathrm{p}^{(1)}=0,377$} \\
\hline & Mediana & 8,72 & 8,74 & \\
\hline & Desvio padrão & 0,43 & 0,35 & \\
\hline \multirow[t]{3}{*}{ - CCS X (1000 céls./mL) } & Média & $3.067,00$ & $1.318,80$ & \multirow[t]{3}{*}{$\mathrm{p}^{(2)}=0,028^{\prime}$} \\
\hline & Mediana & $2.059,00$ & $1.102,00$ & \\
\hline & Desvio padrão & $2.650,66$ & 533,06 & \\
\hline \multirow[t]{3}{*}{ • CBT (1000 UFC/mL) } & Média & $10.534,73$ & $2.081,20$ & \multirow[t]{3}{*}{$\mathrm{p}^{(1)}=0,442$} \\
\hline & Mediana & $1,379,00$ & $1.546,00$ & \\
\hline & Desvio padrão & $23.569,63$ & $2.089,58$ & \\
\hline
\end{tabular}

EST - Extrato Seco Total; ESD - Extrato Seco Desengordurado; CCS - Contagem de Células Somáticas; CBT - Contagem Bacteriana Total 
Tabela 5 - Gordura, lactose, proteína, EST e ESD segundo a CCS por estação do ano (verão e inverno) nas propriedades leiteiras de Miranda do Norte, Itapecurú-Mirim e Santa Rita, MA.

\begin{tabular}{llll}
\hline Variável & CCS & \multicolumn{2}{c}{ Estação do Ano } \\
\cline { 3 - 4 } & & $\begin{array}{c}\text { Verão } \\
\text { Média (DP) }\end{array}$ & $\begin{array}{c}\text { Inverno } \\
\text { Média (DP) }\end{array}$ \\
\hline Gordura & Até 1.000 .000 & $3,65(0,36)$ & $3,74(0,61)$ \\
& $>1.000 .000$ & $3,98(0,72)$ & $3,89(0,65)$ \\
Valor de p & & $\mathrm{p}^{(1)}=0,277$ & $\mathrm{p}^{(1)}=0,724$ \\
Lactose & Até 1.000 .000 & $3,21(0,10)$ & $3,19(0,08)$ \\
& $>1.000 .000$ & $3,17(0,24)$ & $3,28(0,23)$ \\
Valor de p & & $\mathrm{p}^{(2)}=0,610$ & $\mathrm{p}^{(1)}=0,542$ \\
Proteína & Até 1.000 .000 & $4,43(0,23)$ & $4,49(0,03)$ \\
& $>1.000 .000$ & $4,32(0,30)$ & $4,44(0,26)$ \\
Valor de p & & $\mathrm{p}^{(1)}=0,396$ & $\mathrm{p}^{(1)}=0,785$ \\
EST & Até 1.000 .000 & $12,30(0,35)$ & $13,83(0,44)$ \\
& $>1.000 .000$ & $12,23(0,92)$ & $13,07(1,10)$ \\
Valor de p & & $\mathrm{p}^{(2)}=0,798$ & $\mathrm{p}^{(1)}=0,268$ \\
ESD & Até 1.000 .000 & $8,65(0,32)$ & $8,78(0,07)$ \\
& $>1.000 .000$ & $8,50(0,55)$ & $8,74(0,45)$ \\
Valor de $\mathrm{p}$ & & $\mathrm{p}^{(1)}=0,530$ & $\mathrm{p}^{(1)}=0,868$ \\
\hline
\end{tabular}

EST - Extrato Seco Total

ESD - Extrato Seco Desengordurado

CCS - Contagem de Células Somáticas

\section{CONCLUSÃO}

A maioria das amostras deleite analisadasapresenta-sefora dos padrões exigidos pela InstruçãoNormativa No51 do Ministério da Agricultura ,Pecuária e Abastecimento no que serefere à CCSeCBT e dentro dos padrões com relação à composição. Dessa forma, faz-se necessária a introduçãodeum programa deEducaçãoeSaúde junto aos produtores de leite das regiões estudadas, visando a melhoria da qualidade do leite produzido.

\section{REFERÊNCIAS}

ALTMAN, D.G.; HALL, C. Practical statistics for medical research. London: Chapman and Hall, 1991. 611p.

ARAÚJO, V.M.; SILVA, P.D.L.; CORREIA, R.T.P. Variação dos níveis de células somáticas no leite de rebanho bovino potiguar em diferentes períodos do ano. In: CONGRESSO BRASILEIRO DE QUALIDADE DO LEITE, 2., 2006, Goiânia, GO. Resumos. Goiânia: 2006.

BARBOSA, S.B.P.; MONARDES, H.G.; CUE, R.I.; RIBAS, N.P.; BATISTA, A.M.V. Avaliação da contagem de células somáticas na primeira lactação de vacas holandesas no dia do controle mensal. Revista Brasileira de Zootecnia, v.36, n.1, p.223-228, 2007.
BARCELOS, S.S.; OLIVEIRA, L.R.S.; ALVES, K.S.; VERAS, R.M.L.; GOMES, D.I.; ROCHA, P. M. Caracterização físico-química do leite fluido exposto ao consumo no município de Parauapebas - PA. In: CONGRESSO BRASILEIRO DE QUALIDADE DO LEITE, 2., 2006, Goiânia, GO. Resumos. Goiânia: 2006.

BRASIL, Ministério da Agricultura, Pecuária e Abastecimento. Instrução Normativa $N^{\circ} 51$ de 18 de setembro de 2002. Regulamento Técnico de Produção, Identidade e Qualidade do Leite Tipo A, do Leite Tipo B, do Leite Tipo C, do Leite pasteurizado e do leite Cru Refrigerado e o Regulamento Técnico da Coleta de Leite cru Refrigerado e seu Transporte a Granel. Diário Oficial da União, Brasília, DF, 18 de set. de 2002. Secção 3. Disponível em: <http://www.agricultura.gov.br/das/ dipoa/in51.htm>. Acesso em: 25 set. 2002.

BROUNTIN, P. Contagem individual de bactérias no leite no manejo da qualidade. In: DÜRR, J.W.; CARVALHO, M.P.; SANTOS, M.V. (Ed.). O compromisso da qualidade do leite no Brasil. Passo Fundo: UPF, 2004. cap. 26.

BUENO, V.F.F.; MESQUITA, A.L.; NICOLAU, E.S.; OLIVEIRA, A.N.; OLIVEIRA, J.P.; NEVES, R.B.S.; MANSUR, J.R.G.; THOMAZ, L.W. Contagem celular somática: relação com a composição centesimal do leite e período do ano no Estado de Goiás. Ciência Rural, v.35, n.4, p.48-56, 2005.

FERREIRA, L.M.; SOUZA, V.; PINTO, F.R.; NADER, A.F.; MELO, P.C. Avaliação da qualidade físico-química de leite pasteurizado tipo $C$ integral comercializado na cidade de Jaboticabal - SP. In: CONGRESSO BRASILEIRO DE QUALIDADE DO LEITE, 2., 2006, Goiânia, GO. Resumos. Goiânia: 2006.

LANGONI, H. Tendências de modernização do setor lácteo: monitoramento da qualidade do leite pela contagem de células somáticas. Revista de Educação Continuada do CRMV-SP, v.3, p.57-64, 2000.

LIMA, M.C.G.; SENA, M.J.; MOTA, R.A.; MENDES, E.S.; ALMEIDA, C.C.; SILVA, R.P.P.E. Contagem de células somáticas e análises físico-químicas e microbiológicas do leite cru tipo $\mathrm{C}$ produzido na região agreste do estado de Pernambuco. Arquivos do Instituto Biológico, São Paulo, v.73, n.1, p.89-95, 2006.

SANTOS; M.V.; FONSECA, L.F.L. Estratégicas para controle de mastite e melhoria da qualidade do leite. Barueri: Manole, 2007. 314p.

SILVA, J.C.; BENEDETTI, E.; TETZER, T.A. Contagem de células somáticas em amostras de leite cru na região de Catalão, GO. Higiene Alimentar, v.21, n.149, p78-81, 2007

VIANA, L.C. Duração das infecções naturais por estafilococos coagulase negativo e contagem de células 
somáticas em vacas primíparas. 2000. 89f. Dissertação (Mestrado em Sanidade Animal), Universidade Estadual de Londrina, Londrina, 2000.

VIDAL-MARTINS, A.M.C.; ROSSI JÚNIOR, O.D; REZENDE-LAGO, N.C.M. Características físicoquímicas do leite UAT (ultra alta temperatura) ao longo do seu processamento. Higiene Alimentar, v.19, n.3, p.44-48, 2005.
ZAR, E.H. Biostatistical Analysis. New Jersey, Prentice Hall, 1999.

Recebido em $7 / 10 / 08$

Aceito em 20/5/10 